\title{
Exchange Rate Effects on the Volume and Variability of Trade Flows
}

\author{
John T. Barkoulas \\ Department of Economics \\ University of Tennessee \\ Knoxville, TN 37996 USA \\ Christopher F. Baum $\S$ \\ Department of Economics \\ Boston College \\ Chestnut Hill, MA 02467 USA \\ Mustafa Caglayan \\ Department of Economics and Accounting \\ University of Liverpool \\ Liverpool L69 7ZA, UK
}

\begin{abstract}
This paper investigates the effects of exchange rate uncertainty on the volume and variability of trade flows. Employing a signal extraction framework, we show that the direction and magnitude of importers' and exporters' optimal trading activities depend upon the source of the uncertainty (general microstructure shocks, fundamental factors driving the exchange rate process, or a noisy signal of policy innovations), providing a rationale for the contradictory empirical evidence in the literature. We also show that exchange rate uncertainty emanating from general microstructure shocks and the fundamental factors reduces the variability of trade flows, while that related to a noisy signal of policy innovations increases variability.
\end{abstract}

JEL: F11, F17

keywords: trade flows, signal extraction, exchange rate volatility

$\S$ Corresponding author: tel. 617.552.3673, fax 617.552.2308, email baum@bc.edu. 


\section{Exchange Rate Effects on the Volume and Variability of Trade Flows}

\section{Introduction}

Since the breakdown of the Bretton Woods system of fixed exchange rates, both real and nominal exchange rates have fluctuated widely. This volatility has often been cited by the proponents of managed or fixed exchange rates as detrimental, since in their view exchange rate uncertainty will inevitably depress the volume of international trade by increasing the riskiness of trading activity. ${ }^{1}$ Several theoretical studies (e.g. Ethier (1973), Clark (1973), Baron (1976), Cushman (1986), Peree and Steinherr (1989)) have shown that an increase in exchange rate volatility will have adverse effects on the volume of international trade. Other theoretical studies have demonstrated that increased volatility can have ambiguous or positive effects on trade volume: for instance, Viaene and de Vries (1992), who explicitly model the forward market, and Franke (1991) and Sercu and Vanhulle (1992), who consider exporting as an option to a multinational firm facing entry-exit costs in the foreign market.

Given these contradictory theoretical predictions, empirical researchers have examined the effect of both real and nominal exchange rate volatility on the volume of international trade. The overall evidence is best characterized as mixed as the results are sensitive to the choices of sample period, model specification, proxies for exchange rate volatility, and countries considered (developed versus

\footnotetext{
1 The terms uncertainty and volatility are used interchangeably in this paper.
} 
developing). ${ }^{2}$ As Côté's survey of the recent empirical literature concludes, "Despite the widespread view that an increase in volatility will reduce the level of trade, this review reveals that the effects of volatility are ambiguous." (1994, p.v) $)^{3 / 4}$

In this paper, we suggest that in an environment where managers' decisions depend upon both expected return and risk, the relationships between exchange rate uncertainty and both first and second moments of trade flows must be modelled. An analysis which considers only the (often indeterminate) effects of exchange rate uncertainty on the volume of trade will not be capable of generating predictions of optimal behavior. We employ a partial equilibrium approach to evaluate the effects of exchange rate uncertainty, which is modeled as emanating from three relevant sources: general microstructure aspects of the foreign exchange market, the fundamental forces driving the exchange rate process, or a noisy signal of future policy innovations. We analyze the effects of the exchange rate uncertainty introduced through these sources on both the volume and variability of trade flows using a simple signal extraction framework, in which rational economic agents form expectations about the one-period ahead exchange rate based on available information. In a regime of flexible exchange rates, neither importers nor exporters have perfect information regarding the behavior of future exchange rates, since those rates are subjected to a number of shocks. However, making use of all

\footnotetext{
2 Negative effects of exchange rate uncertainty on trade flows are reported by Cushman (1983, 1986, 1988), Akhtar and Hilton (1984), Thursby and Thursby (1987), Kenen and Rodrik (1986), and Peree and Steinherr (1989), among others, while Hooper and Kohlhagen (1978), Gotur (1985), Koray and Lastrapes (1989), and Gagnon (1993) find insignificant effects. Kroner and Lastrapes (1993), using a multivariate GARCH-in-mean model, report that the reduced-form effects of volatility on export volume and prices vary widely. The estimated effects of GARCH conditional variance of the nominal exchange rate on export flows differ in sign and magnitude across the countries studied.

${ }^{3}$ For a survey of theoretical arguments and empirical findings on the relationship between exchange rate volatility and trade flows, see Farell et al. (1983), IMF (1984), Willett (1986) regarding the literature through the mid-1980s, and Côté (1994) for more recent works.

${ }^{4}$ It should be noted that, in almost all cases, the impact of exchange rate volatility on trade flows has been investigated using aggregated data. However, theoretical models predict that firm characteristics and market conditions determine the effects of exchange rate volatility. Hence, it is imperative that disaggregated data should be used to have a better look at this puzzle.
} 
available past information and a noisy signal regarding future policies, agents can form an optimal prediction of future spot rates. As the information content of the signal improves, economic agents will be able to make more accurate forecasts of future exchange rates, which will affect their trading activities. Consequently, the predictability of exchange rates is expected to affect both the volume and variability of trade flows.

Our analytical framework enables us to contribute to the literature in two important ways. First, our theoretical results help reconcile the empirical ambiguity between exchange rate uncertainty and the volume of international trade and demonstrate that the countervailing effects of different sources of volatility are likely to place any seemingly conclusive empirical results in question. We establish relationships between exchange rate volatility and the behavior of trade flows based on channels not previously identified in the literature. Second, we rigorously investigate the relationship between the potential sources of exchange rate volatility and the variability of trade flows, which, to our knowledge, represents the first such investigation in the literature.

The rest of the paper is constructed as follows. Section 2 presents the model used to analyze exchange rate effects on the volume and variability of international trade. Sections 3 and 4 provide the analytical results for the volume and variability of trade, respectively. Section 5 concludes with a summary of our theoretical findings and draws implications for empirical research. 


\section{The Model}

In this section we present a simple signal extraction framework to analyze exchange rate effects on the level and variability of trade flows. To that end we extend the model used by Viaene and de Vries (1992), in which it is assumed that individual merchants have a negligible influence on world market prices. It is also assumed that all invoicing occurs in the foreign currency and consequently domestic firms are exposed to foreign exchange risk. Our approach differs from Viaene and de Vries' in that we allow importers and exporters to acquire limited information on the behavior of exchange rates through a noisy signal. In order to focus on agents' use of information, we do not consider the forward market. ${ }^{5 \cdot 6}$

\subsection{Modelling the Exchange Rate Process}

Each period, importers and exporters decide upon the quantities to import and export, respectively, depending on the exchange rate level expected to prevail over the next period. We assume that the exchange rate, denoted by $\tilde{e}$ and defined as the domestic price of one unit of foreign currency, follows the random process given by

$$
\tilde{e}_{t}=\bar{e}+\varepsilon_{t}+\eta_{t} .
$$

\footnotetext{
${ }^{5}$ Viaene and de Vries (1992) model the effects of the forward market to show that exchange rate volatility can indirectly influence the volume of trade through its effects on the forward rate.

${ }^{6}$ Some researchers have proposed that the use of hedging instruments could possibly eliminate the effects of exchange rate uncertainty on trade. However, there are well-known limitations and costs associated with the usage of currency derivatives. In a recent empirical study, Wei (1999) shows that the availability of hedging instruments cannot explain the observed inconsistent relationship between exchange rate volatility and trade flows.
} 
The first two components of the process in (1) are driven by the fundamental factors determining exchange rate behavior. The deterministic component $\bar{e}$ is the publicly-known mean of the exchange rate process, while $\varepsilon_{t}$ represents the stochastic component of the fundamentals, assumed to follow a first-order autoregressive process, $\varepsilon_{t}=\rho \varepsilon_{t-1}+v_{t}$, where $\rho \in[0,1]$ is a scalar known by all agents and $v_{t} \sim N\left(0, \sigma_{v}^{2}\right)$. We assume that the fundamental factors driving the exchange rate process are related to monetary policy, and that monetary authorities have an information advantage relative to the public over future policy changes affecting the fundamentals, which is reflected in $v_{t} \cdot{ }^{7}$ The process $v_{t}$ is modeled as a normally distributed random variable to capture the fact that the probability of observing small fluctuations in exchange rates due to changes in policymakers' objectives is high, whereas large swings are less probable. Finally, the last component in (1) represents a general "microstructure" shock to the exchange rate process, which is not observable by either the monetary authorities or the public and is modeled as a white noise process, $\eta_{t} \sim N\left(0, \sigma_{\eta}^{2}\right) .8$ We generically refer to a shock as a general microstructure shock if it represents innovations to the exchange rate process arising from the effects of portfolio shifts among international investors (following Evans and Lyons (1999)), excess speculation, bubbles and rumors, bandwagon effects, or the effects of technical trading by chartists or "noise traders". 9 Such shocks are generally short-term in nature and represent temporary excursions from the fundamental value of the exchange rate. In other words, they capture those exchange rate movements that can not be explained by changing expectations of the

\footnotetext{
7 More specifically, relative money supplies, output growth rates, inflation differentials, and interest rate differentials are some of the fundamental factors affecting exchange rate behavior. Monetary policy has a significant impact on the behavior of these fundamental factors.

8 Although it is possible to introduce high-frequency, mean-reverting components in modeling $\eta_{t}$, doing so would complicate the analysis without affecting any of the subsequent results.

9 Taylor and Allen (1992) and Cheung and Chinn (1999) report that foreign exchange dealers rely on technical analysis to form short-term exchange rate predictions, which tend to be self-fulfilling.
} 
underlying economic fundamentals. We assume that the $v_{t}$ and $\eta_{t}$ processes are independent.

The decomposition of the exchange rate process in (1) and its functional form assumptions are consistent at both theoretical and empirical levels. Theoretically, the proposed modeling of the exchange rate process is consistent with the chartistand-fundamentalist approach suggested by Frankel and Froot (1988) and empirically tested by Vigfusson (1996). It is also broadly consistent with the permanenttransitory component decomposition drawn from Mussa's (1982) stochastic generalization of the Dornbusch (1976) exchange-rate overshooting model. Empirically, Mark (1995), Chinn and Meese (1995), and Mark and Sul (1999) show that long-horizon exchange rate movements are determined by economic fundamentals such as relative money stocks and relative real incomes: stochastic processes that are quite persistent. Moreover, the decomposition in (1) directly implies that exchange rate uncertainty is not a truly exogenous variable (as assumed in other theoretical studies) but is rather a function of the underlying volatility in macroeconomic fundamentals.

We assume that economic agents know the fundamentals driving the exchange rate process $\left(\bar{e}, \rho\right.$ and $\sigma_{v}^{2}$ ), and that they observe $\varepsilon_{t-1}$ at the beginning of each period. Making use of this information as well as the knowledge of past exchange rate observations, economic agents may form a forecast of the one-stepahead exchange rate. These forecasts will be imprecise since the monetary authorities can affect foreign exchange market behavior through $v_{t}$. We assume that individuals acquire additional information on the monetary authorities' innovation $v_{t}$ through a noisy signal. This information may include policy announcements, central bank intervention, statements of central bankers or analysts' consensus forecasts as a signal of the stochastic component of the 
fundamentals. ${ }^{10}$ The accuracy of agents' predictions of the one-period ahead exchange rate using knowledge of the fundamentals and a noisy signal on $v_{t}$ depends on the information content of the signal. We characterize the signal by $S_{t}=v_{t}+\psi_{t}$, where $\psi_{t}$ denotes the noise which is assumed to be normally distributed with mean zero and variance $\sigma_{\psi}^{2}$, that is, $\psi_{t} \sim N\left(0, \sigma_{\psi}^{2}\right)$. It is also assumed that $\psi_{t}$ is independent of the $v_{t}$ and $\eta_{t}$ processes. This approach realistically models economic agents' decision-making process, as it takes into consideration their forecasts of economic policies and their expected reactions.

Using linear regression techniques, one can show that $E\left(\varepsilon_{t} \mid S_{t}\right)=\rho \varepsilon_{t-1}+\lambda S_{t}$, where $\lambda S_{t}=E\left(v_{t} \mid S_{t}\right)=\frac{\operatorname{Cov}\left(v_{t}, S_{t}\right)}{\operatorname{Var}\left(S_{t}\right)} S_{t}=\frac{\sigma_{v}^{2}}{\sigma_{v}^{2}+\sigma_{\psi}^{2}} S_{t} .11 \quad$ Furthermore, since $\eta_{t}$ and $S_{t}$ are orthogonal, that is, $E\left(\eta_{t}, S_{t}\right)=0$, the one-period ahead forecast of the exchange rate, conditional on the signal $S_{t}$, may be expressed as

$$
E\left(\tilde{e}_{t} \mid S_{t}\right)=\bar{e}+\rho \varepsilon_{t-1}+\lambda S_{t} .
$$

The first term in (2) is the mean of the exchange rate process, $\bar{e}$, which is known by the public. The remaining terms capture the forecast of the nondeterministic component of $\varepsilon_{t}$ based on the observation of past realizations of the exchange rate and the noisy signal. Hence, using the signal extraction formula in (2), the importer forms a prediction of next period's exchange rate, using all available information along with the signal of future policy innovations to improve upon a naïve (nochange) forecast. Furthermore, equation (2) conveys the idea that the higher is the information content of the signal (the lower is $\sigma_{\psi}^{2}$ ), the more weight agents will place on the signal $S_{t}\left(\right.$ as $\left.\frac{\partial \lambda}{\partial \sigma_{\psi}^{2}}<0\right)$ in order to predict $v_{t}$ and therefore $\tilde{e}_{t}$.

10 Central bank intervention in the foreign exchange market may signal future monetary policy (Kaminsky and Lewis (1996)).

11 This simple application of linear regression allows an agent in an uncertain environment to predict an "unobserved variable in a manner that is optimal, in a certain sense." (Sargent (1987), p. 223) 


\subsection{The Behavior of Importers}

The importer faces a nonstochastic inverse linear demand function $P(Y)=a-\frac{Y}{2}$, where $a>0$ and $P$ and $Y$ denote the price and volume (quantity) of imports, respectively. ${ }^{12}$ Assuming that the nominal price of the imported commodity is one unit of foreign currency, the cost of imports in terms of domestic currency over the next period will be given by $\tilde{e} Y$. Therefore, the profit function of the importer is given by

$$
\tilde{\pi}_{Y}=(a-\tilde{e}) Y-\frac{1}{2} Y^{2}
$$

At each point in time, the importer decides how much to import over the next period, which ultimately depends on the level of the exchange rate expected to prevail over the next period. We assume that the importer maximizes the following expected utility function, which is increasing in expected profits and decreasing in the variance of profits, conditional on the signal $S_{t}$ :

$$
E\left(\tilde{U}_{Y} \mid S_{t}\right)=E\left(\tilde{\pi}_{Y} \mid S_{t}\right)-\frac{1}{2} \gamma_{Y} \operatorname{Var}\left(\tilde{\pi}_{Y} \mid S_{t}\right)
$$

where $\gamma_{Y}$ denotes the coefficient of risk aversion, $0<\gamma_{Y}<\infty .13$ The expected profit and variance functions in equation (4), conditional on the signal $S_{t}$, are given by

\footnotetext{
12 In order to obtain closed-form solutions, as in other studies of information acquisition or sharing, we must assume a linear demand function and an affine information structure as discussed in the text. The same argument holds true when modeling exporters' behavior.

13 The assumption that $\gamma>0$ implies risk aversion. Setting $\gamma=0$ implies risk neutrality while setting $\gamma<0$ implies risk-loving behavior.
} 


$$
\begin{aligned}
& E\left(\tilde{\pi}_{Y} \mid S_{t}\right)=\left(a-\bar{e}-\rho \varepsilon_{t-1}-\lambda S_{t}\right) Y-\frac{Y^{2}}{2} \text { and } \\
& \operatorname{Var}\left(\tilde{\pi}_{Y} \mid S_{t}\right)=E\left(\tilde{\pi}_{Y}-E\left(\tilde{\pi}_{Y} \mid S_{t}\right)\right)^{2}=\left(\sigma_{\psi}^{2} \lambda+\sigma_{\eta}^{2}\right) Y^{2},
\end{aligned}
$$

respectively. Maximization of equation (4) with respect to $Y$ yields the optimal level of imports:

$$
Y=\frac{a-\left(\bar{e}+\rho \varepsilon_{t-1}+\lambda S_{t}\right)}{1+\gamma_{Y}\left(\sigma_{\psi}^{2} \lambda+\sigma_{\eta}^{2}\right)}
$$

In order to obtain an economically meaningful (positive) solution for the optimal level of imports $Y$, the condition $a>\bar{e}+\rho \varepsilon_{t-1}+\lambda S_{t}$ should hold.

\subsection{The Behavior of Exporters}

The exporter incurs a nonstochastic quadratic cost of production $d X+\frac{X^{2}}{2}$, where $d>0$ and $X$ denotes the quantity exported. Normalizing the price of exports denominated in foreign currency to unity, the exporter's random profit function in terms of domestic currency can be written as

$$
\tilde{\pi}_{X}=(\tilde{e}-d) X-\frac{X^{2}}{2} .
$$

The exporter's utility function is given by

$$
E\left(\tilde{U}_{X} \mid S_{t}\right)=E\left(\tilde{\pi}_{X} \mid S_{t}\right)-\frac{1}{2} \gamma_{X} \operatorname{Var}\left(\tilde{\pi}_{X} \mid S_{t}\right)
$$


where $\gamma_{X}$ is the exporter's coefficient of risk aversion, $0<\gamma_{X}<\infty$. Expected profits and the variance of profits in the above equation, conditional on the signal $S_{t}$, are given by

$$
\begin{aligned}
& E\left(\tilde{\pi}_{X} \mid S_{t}\right)=\left(\bar{e}+\rho \varepsilon_{t-1}+\lambda S_{t}-d\right) X-\frac{X^{2}}{2} \text { and } \\
& \operatorname{Var}\left(\tilde{\pi}_{X} \mid S_{t}\right)=E\left(\tilde{\pi}_{X}-E\left(\tilde{\pi}_{X} \mid S_{t}\right)\right)^{2}=\left(\sigma_{\psi}^{2} \lambda+\sigma_{\eta}^{2}\right) X^{2},
\end{aligned}
$$

respectively. Exporters maximize equation (9) with respect to export volume to obtain the optimal level of exports:

$$
X=\frac{\bar{e}+\rho \varepsilon_{t-1}+\lambda S_{t}-d}{1+\gamma_{X}\left(\sigma_{\psi}^{2} \lambda+\sigma_{\eta}^{2}\right)} .
$$

We assume that the condition $\bar{e}+\rho \varepsilon_{t-1}+\lambda S_{t}>d$ is satisfied, which implies an economically meaningful (positive) optimal level of exports.

Throughout the rest of the analysis we assume that all international traders in the economy are equally risk averse, that is, $\gamma_{Y}=\gamma_{X}=\gamma \in(0, \infty)$ for all importers and exporters.

\section{Exchange Rate Volatilities and Trade Volume}

\subsection{Uncertainty from a General Microstructure Shock and Trade Volume}

The stochastic term $\eta_{t}$ in the exchange rate process captures general shocks to exchange rate behavior attributed to microstructure phenomena. At the time agents' trading decisions are made, they are known by neither the public nor the monetary 
authorities. Defining the trade balance $(T B)$ as the difference between total exports and total imports and assuming that there are $m$ exporters and $n$ importers in the domestic economy, we obtain ${ }^{14}$

$$
T B=\sum_{i=1}^{m} X_{i}-\sum_{i=1}^{n} Y_{i}=\frac{(m+n)\left(\bar{e}+\rho \varepsilon_{t-1}+\lambda S_{t}\right)-(m d+n a)}{1+\gamma\left(\sigma_{\psi}^{2} \lambda+\sigma_{\eta}^{2}\right)}
$$

Differentiation of the optimal levels of imports, exports and the trade balance with respect to the variance of the general economic shock, $\sigma_{\eta^{\prime}}^{2}$ yields ${ }^{15}$

$$
\begin{aligned}
& \frac{\partial Y}{\partial \sigma_{\eta}^{2}}=-\frac{\gamma\left(a-\bar{e}-\rho \varepsilon_{t-1}-\lambda S_{t}\right)}{\left[1+\gamma\left(\sigma_{\psi}^{2} \lambda+\sigma_{\eta}^{2}\right)\right]^{2}}<0, \\
& \frac{\partial X}{\partial \sigma_{\eta}^{2}}=-\frac{\gamma\left(\bar{e}+\rho \varepsilon_{t-1}+\lambda S_{t}-d\right)}{\left[1+\gamma\left(\sigma_{\psi}^{2} \lambda+\sigma_{\eta}^{2}\right)\right]^{2}}<0, \text { and } \\
& \frac{\partial T B}{\partial \sigma_{\eta}^{2}}=\frac{-\gamma T B}{1+\gamma\left(\sigma_{\psi}^{2} \lambda+\sigma_{\eta}^{2}\right)} .
\end{aligned}
$$

14 Note that the trade balance could be positive or negative. The number of exporters and importers, $m$ and $n$, respectively, is assumed to be exogenously given. Generally, their numbers will depend on the profitability of the corresponding trading activities, market size and structure, and other factors. We do not address this issue in this paper.

15 The effects of the mean level of exchange rates on the trading volume of importers and exporters and the trade balance are obtained by differentiating equations (7), (12), and (13) with respect to $\bar{e}$, yielding

$$
-\frac{\partial Y}{\partial \bar{e}}=\frac{\partial X}{\partial \bar{e}}=\frac{1}{1+\gamma\left(\sigma_{\psi}^{2} \lambda+\sigma_{\eta}^{2}\right)}>0 \quad \text { and } \quad \frac{\partial T B}{\partial \bar{e}}=\frac{m+n}{1+\gamma\left(\sigma_{\psi}^{2} \lambda+\sigma_{\eta}^{2}\right)}>0
$$

The obtained results are intuitive and consistent with those in the literature (see Viaene and de Vries (1992) and Franke (1991) for example). A currency appreciation (depreciation) increases (decreases) the expected profits of importers (exporters), thus resulting in an increase (decrease) in imports (exports) volume and therefore a decrease (increase) in the trade balance. 
The sign of the derivative in (16) will be opposite to that of the trade balance, that is, it will be positive (negative) in the case of a trade deficit (surplus). The above results can be summarized in the following proposition.

Proposition 1: An increase in the variance of the general microstructure shock in the exchange rate process reduces the volumes of imports and exports. Similarly, the surplus or deficit of the balance of trade is reduced as well.

These results are consistent with earlier findings in the literature. An increase in the variance (volatility) of the general microstructure shock increases the variability of the profit streams of international traders. Under risk aversion, the benefits of international trade are reduced, resulting in a decrease in the volume of international trade. The trade surplus or deficit is reduced as well.

\subsection{Volatility of Fundamentals and Trade Volume}

We now investigate the association between the volatility of the fundamental forces driving the exchange rate process and trade flows. We first differentiate the optimal level of imports in equation (7) with respect to $\sigma_{v}^{2}$ to obtain

$$
\frac{\partial Y}{\partial \sigma_{v}^{2}}=-\frac{\sigma_{\psi}^{2}}{\left(\sigma_{v}^{2}+\sigma_{\psi}^{2}\right)^{2}} \frac{\left[\left(1+\gamma\left(\sigma_{\psi}^{2} \lambda+\sigma_{\eta}^{2}\right)\right) S_{t}+\gamma \sigma_{\psi}^{2}\left(a-\left(\bar{e}+\rho \varepsilon_{t-1}+\lambda S_{t}\right)\right)\right]}{\left[1+\gamma\left(\sigma_{\psi}^{2} \lambda+\sigma_{\eta}^{2}\right)\right]^{2}} .
$$

The sign of the first term in the square brackets depends upon the sign of the signal while the second term is unambiguously positive, given our earlier assumption for obtaining a nontrivial solution for the volume of imports. If the signal is indicative of depreciation $\left(S_{t} \geq 0\right)$, the response of $Y$ to $\sigma_{v}^{2}$ is unambiguously 
negative. However, if the signal is indicative of appreciation $\left(S_{t}<0\right)$, the response of $Y$ to $\sigma_{v}^{2}$ depends upon the parameters of the model. Therefore, the derivative in (17) cannot be signed.

The above effects can be easily traced and analyzed if one considers the impact of an increase in $\sigma_{v}^{2}$ (given the other parameters and the level of imports) on importers' expected profits and the variance of profits. An increase in $\sigma_{v}^{2}$ increases the variance of importers' profits through an increase in $\lambda$, the weight attached to the signal in forming one-step ahead predictions of the exchange rate. This resulting increase in the variability of profits leads to a decrease in the volume of imports due to risk aversion. Contrarily, the effect of $\sigma_{v}^{2}$ on the importers' expected profits is ambiguous, as it depends on the sign of the observed signal $S_{t}$. Given the positive association between $\sigma_{v}^{2}$ and $\lambda$, an increase in $\sigma_{v}^{2}$ will reduce expected profits and the level of imports if $S_{t} \geq 0$ (indicative of currency depreciation) but it will increase expected profits and therefore the level of imports if $S_{t}<0$ (indicative of currency appreciation). Consequently, in the case of a nonnegative signal the effect of increased variance for the fundamentals on the level of imports is unambiguously negative as it decreases expected profits and increases the variability of profits. However, in the case of a negative signal, the effect of an increase in the fundamentals' uncertainty on the level of imports cannot be determined, as increased uncertainty increases the variability of profits while it increases expected profits.

Differentiating the optimal level of exports $X$ with respect to $\sigma_{v}^{2}$ yields

$$
\frac{\partial X}{\partial \sigma_{v}^{2}}=\frac{\sigma_{\psi}^{2}}{\left(\sigma_{v}^{2}+\sigma_{\psi}^{2}\right)^{2}} \frac{\left[\left(1+\gamma\left(\sigma_{\psi}^{2} \lambda+\sigma_{\eta}^{2}\right)\right) S_{t}+\gamma \sigma_{\psi}^{2}\left(d-\left(\bar{e}+\rho \varepsilon_{t-1}+\lambda S_{t}\right)\right)\right]}{\left[1+\gamma\left(\sigma_{\psi}^{2} \lambda+\sigma_{\eta}^{2}\right)\right]^{2}} .
$$


Again, the sign of the response of export volume to the volatility of fundamentals cannot be determined, as the sign of the first term in the square brackets depends upon the sign of the signal $S_{t}$ while the second term is always negative. If the realized signal is positive, then the sign of expression (19) is ambiguous, depending upon the parameters of the model and the realized value of the signal.

Since neither of the signs of these derivatives may be determined, the sign of the corresponding derivative for the trade balance is indeterminate as well. These results can be summarized in the following proposition.

Proposition 2: The effect of the variance of the stochastic elements in the fundamentals driving the exchange rate process on trade flows is ambiguous.

\subsection{Information Content of the Signal and Trade Volume}

As the signal regarding future policy innovations gets noisier (as $\sigma_{\psi}^{2}$ increases), implying that the information content of the signal deteriorates, agents in the economy will put less weight on the signal (since the value of $\lambda$ is lower) in forming expectations of the one-period ahead exchange rate, as given in equation (2). A reduction in the information content of the signal will hinder the ability of agents to make reliable exchange rate forecasts and therefore affect their trading activities.

To analyze the effect of a more informative signal regarding future policy innovations on imports, we differentiate equation (7) with respect to $\sigma_{\psi}^{2}$ to obtain 


$$
\frac{\partial Y}{\partial \sigma_{\psi}^{2}}=\frac{\left[\left(1+\gamma\left(\sigma_{\psi}^{2} \lambda+\sigma_{\eta}^{2}\right)\right) \frac{\sigma_{v}^{2}}{\left(\sigma_{v}^{2}+\sigma_{\psi}^{2}\right)^{2}} S_{t}-\gamma \lambda^{2}\left(a-\left(\bar{e}+\rho \varepsilon_{t-1}+\lambda S_{t}\right)\right)\right]}{\left[1+\gamma\left(\sigma_{\psi}^{2} \lambda+\sigma_{\eta}^{2}\right)\right]^{2}} .
$$

The sign of expression (19) cannot be determined as it depends upon the specific values of the signal and the other parameters of the model. An increase in $\sigma_{\psi}^{2}$ increases the variance of importers' profits, increases expected profits if $S_{t}>0$, and decreases expected profits if $S_{t} \leq 0.16$ Therefore, a sufficient condition for $\frac{\partial Y}{\partial \sigma_{\psi}^{2}}<0$ is that $S_{t} \leq 0$. In the case of a positive-valued signal, the sign of the association between the information content of the signal and the level of imports cannot be determined. In other words, increased noise variance for the signal produces an ambiguous response if the signal is positive.

Similarly, differentiation of the optimal export volume with respect to $\sigma_{\psi}^{2}$ yields

$$
\frac{\partial X}{\partial \sigma_{\psi}^{2}}=-\frac{\left[\left(1+\gamma\left(\sigma_{\psi}^{2} \lambda+\sigma_{\eta}^{2}\right)\right) \frac{\sigma_{v}^{2}}{\left(\sigma_{v}^{2}+\sigma_{\psi}^{2}\right)^{2}} S_{t}-\lambda^{2}\left(d-\left(\bar{e}+\rho \varepsilon_{t-1}+\lambda S_{t}\right)\right)\right]}{\left[1+\gamma\left(\sigma_{\psi}^{2} \lambda+\sigma_{\eta}^{2}\right)\right]^{2}}
$$

which, following similar logic, cannot be unambiguously signed. It follows that the response of the trade balance to the information content of the signal is indeterminate.

These results are summarized in the following proposition.

16 For a given level of $Y$, the overall effect of $\sigma_{\psi}^{2}$ on the variability of importers' profits is positive as $\frac{\partial \operatorname{Var}\left(\tilde{\pi}_{Y} \mid S_{t}\right)}{\partial \sigma_{\psi}^{2}}=Y^{2} \lambda^{2}>0$. 
Proposition 3: The effect of the variance of the noise of the signal regarding future policies on trade flows is ambiguous.

Empirical researchers have obtained contradictory results when testing the relationship between exchange rate volatility and the volume of trade. As mentioned in the introductory section, positive, negative as well as statistically insignificant associations between exchange rate volatility and trade flows have been reported. Propositions 2 and 3 provide a rationale for those findings, as well as the intuition as to why such contradictory empirical evidence might have been obtained..$^{17}$

\section{Exchange Rate Volatilities and Variability of Trade Flows}

We now consider the linkages between exchange rate volatility and the variability of imports, exports, and the trade balance: a relationship of considerable importance, since it directly relates to smoothing the business cycle, which is an important argument in the macro welfare function. Previous theoretical work has only considered linkages between exchange rate volatility and the first moment (level) of trade flows. Nevertheless, it is essential to analyze the underlying causes of the volatility of trade flows, as knowledge of the second moments is necessary to fully characterize the behavior of trade flows. These effects are of particular importance in small, open economies under a flexible exchange rate system. In those economies, the importance of international trade is sizeable, and variability of trade flows can significantly impact the variability of the overall level of economic

17 This ambiguity is in accordance with Viaene and deVries' (1992) findings. Even if forward market hedging opportunities exist, exporters and importers are on opposite sides of the forward market. 
activity. Such instability may result in financial sector illiquidity, reductions in real output, and/or heightened inflationary pressures.

We can obtain the variances of imports, exports, and the trade balance noting that the random nature of these variables is wholly derived from the signal $S_{t}$, conditional on other parameters and information known to the agent at time $t-1$. Using equations (7), (12), and (13), the variances of imports, exports, and the trade balance can be derived as follows: 18

$$
\begin{aligned}
& \operatorname{Var}(Y)=\operatorname{Var}(X)=\frac{\lambda \sigma_{v}^{2}}{\left[1+\gamma\left(\sigma_{\psi}^{2} \lambda+\sigma_{\eta}^{2}\right)\right]^{2}} \text {, and } \\
& \operatorname{Var}(T B)=(m+n)^{2} \operatorname{Var}(X)=(m+n)^{2} \operatorname{Var}(Y)=(m+n)^{2} \frac{\lambda \sigma_{v}^{2}}{\left[1+\gamma\left(\sigma_{\psi}^{2} \lambda+\sigma_{\eta}^{2}\right)\right]^{2}} .
\end{aligned}
$$

We may now proceed to analyze the effect of exchange rate variances on the variability of trade flows.

\subsection{Uncertainty from a General Microstructure Shock and Variability of Trade} Flows

Differentiation of equations (21) and (22) with respect to the variance of a general microstructure shock, $\sigma_{\eta^{\prime}}^{2}$ yields the corresponding responses of the variability of trade flows. They are given by

\footnotetext{
18 If the unconditional variances of these variables are of interest, that is, the variances derived without conditioning on the information set at time $t-1$, then, in order to obtain finite second moments, $\rho$ should be strictly less than unity.
} 


$$
\begin{aligned}
& \frac{\partial \operatorname{Var}(Y)}{\partial \sigma_{\eta}^{2}}=\frac{\partial \operatorname{Var}(X)}{\partial \sigma_{\eta}^{2}}=-\frac{2 \gamma \lambda \sigma_{v}^{2}}{\left[1+\gamma\left(\sigma_{\psi}^{2} \lambda+\sigma_{\eta}^{2}\right)\right]^{3}}<0 \text { and } \\
& \frac{\partial \operatorname{Var}(T B)}{\partial \sigma_{\eta}^{2}}=-(m+n)^{2} \frac{2 \gamma \lambda \sigma_{v}^{2}}{\left[1+\gamma\left(\sigma_{\psi}^{2} \lambda+\sigma_{\eta}^{2}\right)\right]^{3}}<0 .
\end{aligned}
$$

Increased volatility in the general microstructure environment, emanating from innovations unforeseen by both the monetary authorities and the public, leads to higher exchange rate volatility, and thus a reduction in the variability of trading activities. These results are summarized in the following proposition.

Proposition 4: The variances of imports, exports, and the trade balance are negatively related to the variance of the general microstructure term in the exchange rate process.

\subsection{Uncertainty of the Fundamentals and Variability of Trade Flows}

We now turn to the response of variability of trade flows to a change in the variance of the fundamental factors driving the exchange rate process. Differentiation of equations (21) and (22) with respect to $\sigma_{v}^{2}$ yields

$$
\begin{aligned}
& \frac{\partial \operatorname{Var}(Y)}{\partial \sigma_{v}^{2}}=\frac{\partial \operatorname{Var}(X)}{\partial \sigma_{v}^{2}}=\lambda \frac{(2-\lambda)\left(1+\gamma \sigma_{\eta}^{2}\right)+\gamma \lambda^{2} \sigma_{\psi}^{2}}{\left[1+\gamma\left(\sigma_{\psi}^{2} \lambda+\sigma_{\eta}^{2}\right)\right]^{3}}>0 \text { and } \\
& \frac{\partial \operatorname{Var}(T B)}{\partial \sigma_{v}^{2}}=(m+n)^{2} \lambda \frac{(2-\lambda)\left(1+\gamma \sigma_{\eta}^{2}\right)+\gamma \lambda^{2} \sigma_{\psi}^{2}}{\left[1+\gamma\left(\sigma_{\psi}^{2} \lambda+\sigma_{\eta}^{2}\right)\right]^{3}}>0 .
\end{aligned}
$$


An increase in the volatility of the fundamental forces driving the exchange rate process is partially observed by economic agents via the noisy signal. Therefore, its potential effects can be incorporated in the decision making process and agents will readjust their optimal import and export volumes in response to increased fundamentals' uncertainty thus leading to greater variability of trade flows. This is in contrast to the effects of increased volatility in the general microstructure environment previously considered, in which case, increased exchange rate volatility cannot be predicted by economic agents. These results are summarized in the following proposition.

Proposition 5: The variances of imports, exports, and the trade balance are positively related to the variance of the fundamental forces driving the exchange rate process.

\subsection{The Information Content of the Signal and Variability of Trade Flows}

Finally, we investigate the effect of the information content of the signal, which is used to predict future exchange rates, on the variability of trade flows. These relationships can be investigated by computing the derivatives of the import, export, and trade balance variance equations with respect to the variance of the noise, $\sigma_{\psi}^{2}$. Using equations (21) and (22), we obtain

$$
\frac{\partial \operatorname{Var}(Y)}{\partial \sigma_{\psi}^{2}}=\frac{\partial \operatorname{Var}(X)}{\partial \sigma_{\psi}^{2}}=-\frac{\sigma_{v}^{2}\left(\left(1+\gamma\left(\sigma_{\psi}^{2} \lambda+\sigma_{\eta}^{2}\right)\right) \frac{\lambda}{\sigma_{v}^{2}+\sigma_{\psi}^{2}}+2 \gamma \lambda^{3}\right)}{\left[1+\gamma\left(\sigma_{\psi}^{2} \lambda+\sigma_{\eta}^{2}\right)\right]^{3}}<0
$$

and 


$$
\frac{\partial \operatorname{Var}(T B)}{\partial \sigma_{\psi}^{2}}=-(m+n)^{2} \frac{\sigma_{v}^{2}\left(\left(1+\gamma\left(\sigma_{\psi}^{2} \lambda+\sigma_{\eta}^{2}\right)\right) \frac{\lambda}{\sigma_{v}^{2}+\sigma_{\psi}^{2}}+2 \gamma \lambda^{3}\right)}{\left[1+\gamma\left(\sigma_{\psi}^{2} \lambda+\sigma_{\eta}^{2}\right)\right]^{3}}<0
$$

If $\sigma_{\psi}^{2}$ increases, the ability of economic agents to make accurate predictions of the one-period ahead exchange rate is reduced as the information content of the signal deteriorates. Agents will become more conservative in their responses to the observed signal, leading to smaller fluctuations in their optimally chosen level of trading activity. Conversely, if the signal is a more accurate predictor of future policy innovations, agents will take advantage of this increased information content and adjust their trading volume more vigorously, leading to a higher volatility of trade flows. These results are summarized in the following proposition.

Proposition 6: An improvement (deterioration) in the accuracy of future exchange rate predictions due to a decrease (increase) in the variance of the noise of the signal causes the variances of imports, exports, and the trade balance to increase (decrease).

We have identified three sources of variability in the exchange rate process: general microstructure shocks, the stochastic behavior of the fundamentals, and the noise blurring the signal of future policy innovations. While greater variability in the process generating general microstructure shocks is associated with less variable trade flows (Prop. 4), greater variability in the fundamentals driving the exchange rate process is actually related to more volatile trade flows (Prop. 5). A noisier signal has the intuitive result of reducing the variance of trade flows as agents become more cautious in their responses (Prop. 6). Therefore, we find justification for both increases and decreases in the variability of trade flows in response to exchange rate 
volatility, with the overall direction of change depending upon the sources and magnitudes of those volatilities. ${ }^{19}$

\section{Conclusions}

In this paper, we have developed a simple signal extraction framework to investigate the effects of exchange rate uncertainty on the volume and variability of trade flows. This framework enables us to identify the effects of three different sources of exchange rate uncertainty, which are associated with a general microstructure shock, the behavior of the exchange rate fundamentals, and the signaling process of future policy innovations. We also add to the previous literature by investigating the relationship between exchange rate uncertainty and the variability of trade flows.

We show that the variance of microstructure shocks to the exchange rate process negatively affects both the level and the variability of trade flows. However, the variances of exchange rate fundamentals and the noise of the signal of future policy innovations have an ambiguous effect on the level of trade flows but positive and negative effects, respectively, on the variability of trade flows. Our analytical results therefore help reconcile the contradictory empirical findings in the exchange rate uncertainty-trading volume relationship, and demonstrate that countervailing effects of different sources of volatility are likely to place any seemingly conclusive empirical results in question. Simply studying the total effect of exchange rate uncertainty is likely to lead to quite misleading inferences regarding the underlying relationship. As the source of exchange rate uncertainty does matter in determining

\footnotetext{
19 In a model of firms who may choose to enter or exit foreign markets, a "real options" framework has been utilized to demonstrate that increased volatility enhances the value of the option to enter (exit) the market, and causes firms to adopt a "wait and see" attitude. Dixit (1989) shows that this causes firms to become less responsive to exchange rate movements.
} 
its ultimate effect on the behavior of trade flows, empirical researchers should attempt to estimate the components of exchange rate uncertainty and evaluate their specific effects on trade volume and trade volatility.

\section{Acknowledgements}

We are grateful to two anonymous reviewers for their constructive suggestions on an earlier draft of the paper. The standard disclaimer applies. 


\section{References}

Akhtar, M. A., Hilton, R. S., 1984. Exchange rate uncertainty and international trade: Some conceptual issues and new estimates from Germany and the U.S.. Federal Reserve Bank of New York, Research Paper No. 8403.

Baron, D. P., 1976. Fluctuating exchange rates and the pricing of exports. Economic Inquiry 14 (3), 425-438.

Cheung, Y., Chinn, M., 1999. Macroeconomic implications of the beliefs and behavior of foreign exchange traders. Working Paper, Department of Economics, University of California at Santa Cruz.

Chinn, M. D., Meese, R. A., 1995. Banking on currency forecasts: How predictable is change in money? Journal of International Economics 38 (1-2), 161-178.

Clark, P. B., 1973. Uncertainty, exchange risk, and the level of international trade. Western Economic Journal 11 (3), 302-313.

Côté, A., 1994. Exchange rate volatility and trade: A survey. Working Paper 94-5, Bank of Canada.

Cushman, D. O., 1983. The effects of real exchange rate risk on international trade. Journal of International Economics 15 (1-2), 45-63.

Cushman, D. O., 1986. Has exchange rate risk depressed international trade? The impact of third-country exchange risk. Journal of International Money and Finance 5 (3), 361-379.

Cushman, D. O., 1988. U.S. bilateral trade flows and exchange risk during the floating period. Journal of International Economics 24 (3-4), 317-330.

Dixit, A., 1989. Entry and exit decisions under uncertainty. Journal of Political Economy 97 (3), 620-638. 
Dornbusch, R., 1976. Expectations and exchange rate dynamics. Journal of Political Economy 84 (6), 1161-1176.

Ethier, W., 1973. International trade and the forward exchange market. American Economic Review 63 (3), 494-503.

Evans, M. , Lyons, R., 1999. Order flow and exchange rate dynamics. Working paper, Haas School of Business, University of California at Berkeley.

Farell, V. S., DeRosa, D. A., McCown, T. A., 1983. Effects of exchange rate variability on international trade and other economic variables: A review of the literature. Staff Study No. 130, Board of Governors of the Federal Reserve System.

Franke, G., 1991. Exchange rate volatility and international trading strategy. Journal of International Money and Finance 10 (2), 292-307.

Frankel, J., Froot, K., 1988. Chartists, fundamentalists, and the demand for dollars. Greek Economic Review 10 (1), 49-102.

Gagnon, J. E., 1993. Exchange rate variability and the level of international trade. Journal of International Economics 34 (3-4), 269-287.

Gotur, D., 1985. Effects of exchange rate volatility on trade: Some further evidence. IMF Staff Papers 32 (3), 475-512.

Hooper, P., Kohlhagen, S. W., 1978. The effect of exchange rate uncertainty on the prices and volume of international trade. Journal of International Economics 8 (4), 483-511.

International Monetary Fund, 1984. Exchange rate volatility and world trade. IMF Occasional Papers No. 28, International Monetary Fund, Washington, DC.

Kaminsky, G. L., Lewis, L. K., 1996. Does foreign exchange rate intervention signal future monetary policy? Journal of Monetary Economics 37 (2), 285-312. 
Kenen, P. B., Rodrik, D., 1986. Measuring and analyzing the effect of short term volatility in real exchange rates. Review of Economics \& Statistics 68 (2), 311-315.

Koray, F., Lastrapes, W. D., 1989. Real exchange rate volatility and U.S. bilateral trade: A VAR approach. Review of Economics \& Statistics 71 (4), 708-712.

Kroner, K., Lastrapes, W. D., 1993. The impact of exchange rate volatility on international trade: Reduced form estimates using the GARCH-in-mean model. Journal of International Money and Finance 12 (3), 298-318.

Mark, N. C., 1995. Exchange rates and fundamentals: Evidence on long-horizon predictability. American Economic Review 85 (1), 201-218.

Mark, N. C., Sul, D., 1999. Nominal exchange rates and monetary fundamentals: Evidence from a small post-Bretton Woods panel. Working Paper, Department of Economics, Ohio State University.

Mussa, M. L., 1982. A model of exchange rate dynamics. Journal of Political Economy 90 (1), 74-104.

Peree, E., Steinherr, A., 1989. Exchange rate uncertainty and foreign trade. European Economic Review 33 (6), 1241-1264.

Sargent, T., 1987. Macroeconomic Theory. Academic Press, Boston, MA.

Sercu, P., Vanhulle, C., 1992. Exchange rate volatility, international trade, and the value of exporting firm. Journal of Banking and Finance 16 (1), 152-182.

Taylor, M. P., Allen, H., 1992. The use of technical analysis in the foreign exchange market. Journal of International Money and Finance 11 (3), 304-314.

Thursby, J. G., Thursby, M. C., 1987. Bilateral trade flows, the Linder hypothesis and exchange rate risk. Review of Economics \& Statistics, 69 (3), 488-495.

Viaene, J. M., de Vries, C. G., 1992. International trade and exchange rate volatility. European Economic Review 36 (6), 1311-1321. 
Vigfusson, R., 1996. Switching between chartists and fundamentalists: A Markov regime-switching approach. Working Paper 96-1, Bank of Canada.

Wei, S., 1999. Currency hedging and goods trade. European Economic Review 43 (7), 1371-1394.

Willett, T. D., 1986. Exchange rate volatility, international trade, and resource allocation: A perspective on recent research. Journal of International Money and Finance 5 (0), S101-S112. 